\title{
Endoscopic ultrasound-guided gallbladder drainage, transpapillary drainage, or percutaneous drainage in high risk acute cholecystitis patients: a systematic review and comparative meta-analysis
}

Authors

Babu P. Mohan', Shahab R. Khan¹, Sushruth Trakroo², Suresh Ponnada3 ${ }^{3}$ Mahendran Jayaraj ${ }^{4}$, Ravishankar Asokkumar $^{5}$, Douglas G. Adler ${ }^{6}$

Institutions

1 Internal Medicine, University of Arizona, Banner University Medical Center, Tucson, Arizona, United States

2 Internal Medicine, St. Vincent Charity Medical Center, Cleveland, Ohio, United States

3 Carilion Roanoke Memorial Hospital, Roanoke, Virginia, United States

4 Department of Gastroenterology and Hepatology, University of Nevada, Las Vegas, Nevada, United States

5 Department of Gastroenterology and Hepatology, Singapore General Hospital, Singapore

6 Division of Gastroenterology and Hepatology, University of Utah School of Medicine, Salt Lake City, Utah, United States

submitted 8.4.2019

accepted after revision 3.9.2019

Bibliography

DOI https://doi.org/10.1055/a-1020-3932

Published online: 23.10.2019 | Endoscopy 2020; 52: 96-106

(c) Georg Thieme Verlag KG Stuttgart · New York

ISSN 0013-726X

Corresponding author

Douglas G. Adler MD, Gastroenterology and Hepatology, University of Utah School of Medicine, Huntsman Cancer Center, 30N 1900E 4R118, Salt Lake City, Utah 84132, United States

Fax: +1-801-581-8007

Douglas.adler@hsc.utah.edu

丹 Supplementary material

Online content viewable at:

https://doi.org/10.1055/a-1020-3932
\# Scan this QR-Code for the author commentary.

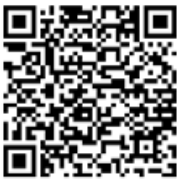

ABSTRACT

Background Endoscopic transpapillary gallbladder drainage (ETGBD) and endoscopic ultrasound-guided gallbladder drainage (EUSGBD) are alternatives to percutaneous gallbladder drainage (PCGBD) for patients with acute cholecystitis who are unfit for surgery. Data comparing these modalities are limited and have reported conflicting results.

Methods We searched multiple databases from inception to May 2019 to identify studies that reported on ETGBD, EUSGBD, and PCGBD in the management of acute cholecystitis in patients with a high surgical risk. Aims were to compare the pooled rates of technical success, clinical success, adverse events, and disease recurrence.

Results 1223 patients (22 studies), 557 patients (14 studies), and 13351 patients (46 studies) were treated by ETGBD, EUSGBD, and PCGBD, respectively. The pooled technical and clinical successes were: ETGBD 83\% (95\% confidence interval $\left.[\mathrm{Cl}] 80.1-85.5, R^{2}=29\right)$ and $88.1 \%$ $\left(95 \% \mathrm{Cl} 83.6-91.4, R^{2}=50\right)$, respectively; EUSGBD $95.3 \%$ $\left(95 \% \mathrm{Cl} 92.8-96.9, R^{2}=0\right)$ and $96.7 \%(95 \% \mathrm{Cl} 94.0-98.2$, $\left.R^{2}=0\right)$, respectively; and PCGBD $98.7 \%(95 \% \mathrm{Cl} 98.0-99.1$, $\left.R^{2}=0\right)$ and $89.3 \%\left(95 \% \mathrm{Cl} 86.6-91.5, R^{2}=84\right)$, respectively. Clinical success with EUSGBD was significantly superior to the other approaches. All complications were comparable between the groups. Pancreatitis occurred with ETGBD in $5.1 \%(95 \% \mathrm{Cl} 3.5-7.3)$, whereas bleeding and perforation occurred with EUSGBD in $4.3 \%(95 \% \mathrm{Cl} 2.7-6.8)$ and 3.7 $\%(95 \% \mathrm{CI} 2.3-6.0)$, respectively. Stent migration occurred with PCGBD in $7.4 \%(95 \% \mathrm{Cl} 5.5-10.0)$.

Conclusion EUSGBD demonstrated better clinical success than ETGBD and PCGBD in the management of acute cholecystitis patients at high surgical risk. 


\section{Introduction}

Acute cholecystitis is usually treated by laparoscopic cholecystectomy as the standard of care [1]. In situations where patients are not fit for surgery, percutaneous or endoscopic routes can be used to decompress the gallbladder. Percutaneous options for gallbladder drainage (GBD) include simple needle aspiration or percutaneous gallbladder drainage (PCGBD) that is traditionally done via interventional radiology with the placement of a double-pigtail plastic catheter as the drainage tool. Technical success rates with PCGBD range from $97 \%$ to $100 \%$, with clinical success in the range of $56 \%$ to $100 \%$ [2].

PCGBD has its limitations, however. Adverse events in the range of $10 \%-12 \%$ have been reported, and worsening of cholecystitis is in the range of $25 \%-50 \%$ [3]. Endoscopic options to drain the gallbladder have evolved rapidly in recent years. Options include endoscopic transpapillary gallbladder drainage (ETGBD) and endoscopic ultrasound (EUS)-guided gallbladder drainage (EUSGBD). ETGBD and EUSGBD have the advantage of offering the patient internal drainage without the need for percutaneous tubes, with all of their attendant downsides.

Several studies have compared the performance of EUSGBD and/or ETGBD with that of PCGBD, with conflicting results [48]. As a result, the role of endoscopy in the management algorithm of acute cholecystitis has not been confirmed. Furthermore, data comparing ETGBD and EUSGBD are limited. We conducted this meta-analysis to better understand and compare the clinical outcomes of ETGBD, EUSGBD, and PCGBD in highrisk acute cholecystitis patients.

\section{Methods}

\section{Search strategy}

We conducted a comprehensive search of several databases and conference proceedings including EBM reviews, Embase, Medline, Scopus, Web of Science, and ClinicalTrials.gov (earliest inception to May 2019). We followed the Preferred Reporting Items for Systematic Reviews and Meta-Analyses (PRISMA) and the Meta-analyses Of Observational Studies in Epidemiology (MOOSE) checklists $[9,10]$ by using a predefined protocol to identify studies reporting on GBD in high risk patients diagnosed with acute cholecystitis. An experienced medical librarian using inputs from the study authors helped with the literature search. The PRISMA and MOOSE checklists are provided in the supplementary appendix (see the online-only supplementary material).

Details of the search strategy including the key words used are detailed in the supplementary appendix. The search was restricted to studies in human subjects and published in the English language in peer-reviewed journals. Two authors (B.P.M. and S.T.) independently reviewed the title and abstract of studies identified in primary search and excluded studies that did not address the research question, based on prespecified exclusion and inclusion criteria. The full text of remaining articles was reviewed to determine whether it contained relevant information. Any discrepancy in article selection was resolved by consensus, and in discussion with a co-author.
The bibliographic sections of the selected articles, as well as the systematic and narrative articles on the topic, were manually searched for additional relevant articles.

\section{Study selection}

We included studies that evaluated the performance of ETGBD, EUSGBD, and PCGBD in patients with acute cholecystitis who were considered high risk for immediate cholecystectomy owing to age and/or underlying chronic disease processes such as malignancy. Studies were included irrespective of the presence or absence of gallstones, underlying liver cirrhosis, inpatient/ outpatient setting, geography, or abstract/manuscript status, as long as they provided data needed for the analysis.

Exclusion criteria were: 1) studies on GBD for malignant stricture of the bile ducts, 2) studies with a sample size of fewer than 10 patients, 3) studies conducted in a pediatric population (age $<18$ years), and 4) studies not published in the English language.

In cases of multiple publications from the same cohort and/ or overlapping cohorts, data from the most recent and/or most appropriate comprehensive report were included. Primary authors were contacted via email for further clarification if needed.

\section{Data abstraction and quality assessment}

Data on study-related outcomes in the individual studies were abstracted onto a standardized form by at least three authors (B.P.M., S.R.K. and S.T.), and two authors (S.R.K. and B.P.M.) completed the quality scoring independently.

For randomized trials and case - control studies, data collection was performed as number of reported events ( $n$ ) out of total number of patients $(\mathrm{N})$ from each study. The collected data were treated akin to single group cohort studies and therefore we used the Newcastle-Ottawa scale for cohort studies to assess the quality of data for bias [11]. This quality score consisted of eight questions, the details of which are provided in Table $1 \mathrm{~s}$ in the online-only supplementary material.

\section{Outcomes assessed}

The following outcomes were assessed for ETGBD vs. EUSGBD vs. PCGBD: pooled rate of technical success, pooled rate of clinical success, pooled rate of adverse events, pooled rate of disease recurrence, pooled rate of all-cause mortality.

\section{Assessment methodology and definitions}

The collected data were matched between the groups (ETGBD, EUSGBD, and PCGBD) before statistical analysis. Although, this model of comparison is indirect and should be considered weak when compared with a randomized controlled trial, the approach is comparable to a retrospective case - control study with matched groups [12].

\section{Acute cholecystitis diagnosis}

Patients were diagnosed as having acute cholecystitis based on the following criteria derived from the Tokyo guidelines: clinical symptoms of right upper quadrant and/or epigastric pain or tenderness; signs of systemic inflammation including fever 
and high white blood cell count or high levels of C-reactive protein; and positive findings associated with distended gallbladder, thickening of the wall of the gallbladder or, fluid around the gallbladder, as confirmed on abdominal ultrasonography or computed tomography and/or positive Murphy's sign [13].

\section{Definition of outcomes}

Technical success was defined as successful placement of the catheter into the gallbladder with confirmed drainage. Clinical efficacy was evaluated based on the improvement in white blood cell count, serum bilirubin levels, C-reactive protein levels, and improvement in patient symptoms. The clinical success rate was calculated for patients in whom technical success was achieved, and not for all patients in whom drainage was attempted.

Recurrence of acute cholecystitis was defined as the new onset of typical symptoms of acute cholecystitis and/or cholangitis with imaging findings after a documented clinical success.

Adverse events were defined as any procedure-, drain- or stent-related event. When reported, the American Society of Gastrointestinal Endoscopy (ASGE) lexicon definitions were used to classify the data [14].

\section{Statistical analysis}

We used meta-analysis techniques to calculate the pooled estimates in each case following the methods suggested by DerSimonian and Laird using the random effects model [15]. When the incidence of an outcome was zero in a study, a continuity correction of 0.5 was added to the number of incident cases before statistical analysis [16]. Statistical significance to the difference between the cohorts assessed was set a priori at a $P$ value of $\leq 0.05$ as determined by the statistical software based on the analyzed outcomes between the cohorts. We assessed heterogeneity between study-specific estimates by using Cochran Q statistical test for heterogeneity, 95\% prediction interval (PI), which deals with the dispersion of the effects [17 - 19], and the $I^{2}$ statistics $[20,21]$. For this, values of $<30 \%, 30 \%-60 \%, 61 \%-$ $75 \%$, and $>75 \%$ were suggestive of low, moderate, substantial, and considerable heterogeneity, respectively [22]. Publication bias was ascertained, qualitatively, by visual inspection of a funnel plot and quantitatively by the Egger test [23]. When publication bias was present, further statistics using the fail-Safe $\mathrm{N}$ test and Duval and Tweedie's "Trim and Fill” test was used to ascertain the impact of the bias [24]. Three levels of impact were reported based on the concordance between the reported results and the actual estimate if there was no bias. The impact was reported as minimal if both versions were estimated to be the same, modest if effect size changed substantially but the final finding would still remain the same, and severe if the basic final conclusion of the analysis is threatened by the bias [25].

All analyses were performed using Comprehensive Meta-Analysis software, version 3 (BioStat, Englewood, New Jersey, USA).

\section{Results}

\section{Search results and population characteristics}

From an initial total of 2591 studies, 129 records were screened and 101 full-text articles were assessed. A total of 72 studies were included in the final analysis [3-8, 26-91]. The flow diagram of study selection is shown in Fig. 1 s.

In our search process, we encountered at least seven studies that had overlapping cohorts [8, 28, 33, 60, 92-94]. The most comprehensive study was included in this analysis. The studies by Irani et al. [5], and Dollhopf et al. [28], had potential overlap of patients managed with EUSGBD at the Prince of Wales Hospital, Hong Kong. Both studies were included in the analysis and any potential statistical bias was evaluated by sensitivity analysis. In the study by Kedia et al. [34], endoscopic GBD (combination of ETGBD and EUSGBD) was compared with PCGBD, and the data on PCGBD were extracted.

Overall, 22 studies provided data on $\operatorname{ETGBD}[3,4,29,30,32$, $35-41,43,59,63,74,76,80,82,85-87], 14$ studies provided data on EUSGBD [5-8, 26-28, 31, 33, 41, 42, 44, 59, 85], and 46 studies provided information on PCGBD for the analysis [3$8,30,34,45-58,60-62,64-73,75,77-79,81,83,84,88$ 91].

Baseline population characteristics were comparable between the three groups. The mean and/or median age ranged from 65 years to 85 years, with a predominantly male population (61\%). Basic population characteristics are described in Table $2 \mathrm{~s}$.

\section{Characteristics and quality of included studies}

Seven of the 72 studies were prospective $[6,8,29,36,44,63$, 86 ], including one randomized study [63], and the rest were retrospective in nature. A total of 14 studies [3, 5, 7, 8, 28, 31, $33,36,44,53,63,79,85,91]$ were from multicenter settings and the rest were single-center studies. One study was population based from the National Inpatient Sample (NIS) database [47]. All studies reported adequately on the clinical outcomes, assessment, and the basic patient factors were comparable between the study groups. Based on the risk of bias scoring system, 37 studies were considered of high quality [3,5-8,26, $28,30,31,33,34,36,37,39,41,44,45,48,52,53,58-61,63-$ $65,68,69,71,75-78,80,85,90], 33$ studies were of medium quality $[4,27,29,32,35,38,40,42,43,46,49-51,54-57,62$, $66,67,70,72,74,79,81-84,86-89,91]$, and two studies were considered to be of low quality $[47,73]$. The detailed assessment of study quality is given in Table $1 \mathrm{~s}$.

\section{Meta-analysis outcomes}

A total of 15131 patients were included in the analysis from 72 studies [3-8,26-91], 1223 patients from 22 studies were treated with ETGBD $[3,4,29,30,32,35-41,43,59,63,74,76$, $80,82,85-87$ ], 557 patients from 14 studies were treated by EUSGBD $[5-8,26-28,31,33,41,42,44,59,85]$, and 13351 patients from 46 studies were treated by PCGBD [3 - 8, 30, 34, $45-58,60-62,64-73,75,77-79,81,83,84,88-91]$. 


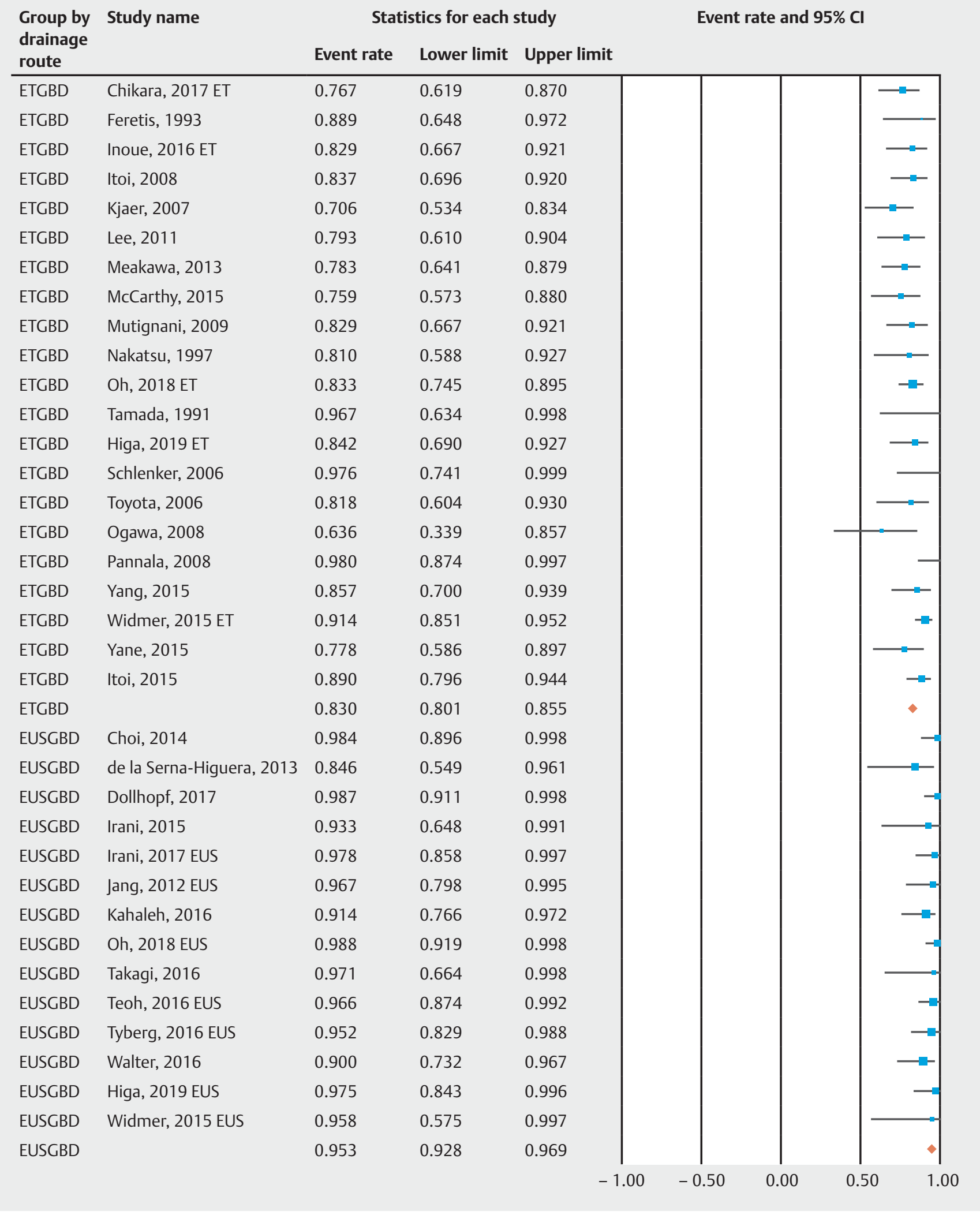

Fig. 1 Technical success rates of gallbladder drainage methods. 
- Table 1 Meta-analysis results.

\begin{tabular}{|c|c|c|c|c|}
\hline & Technical success & Clinical success & Adverse events & Recurrence \\
\hline \multicolumn{5}{|c|}{ Pooled rates, $\%\left(95 \% \mathrm{Cl}, I^{2}\right)$} \\
\hline - ETGBD & $\begin{array}{l}83 \%(80.1-85.5,29) \\
\text { ( } 21 \text { studies, } 851 \text { patients })\end{array}$ & $\begin{array}{l}88.1 \%(83.6-91.4,50) \\
\text { (22 studies, } 1223 \text { patients) }\end{array}$ & $\begin{array}{l}9.6 \%(5.9-15.3,27) \\
\text { ( } 21 \text { studies, } 1209 \text { patients) }\end{array}$ & $\begin{array}{l}4.6 \%(2.8-7.4,53) \\
\text { ( } 22 \text { studies, } 1223 \text { patients) }\end{array}$ \\
\hline - EUSGBD & $\begin{array}{l}95.3 \%(92.8-96.9,0) \\
\text { (14 studies, } 557 \text { patients) }\end{array}$ & $\begin{array}{l}96.7 \%(94.0-98.2,0) \\
(14 \text { studies, } 557 \text { patients })\end{array}$ & $\begin{array}{l}12.4 \%(6.9-21.1,6) \\
\text { (13 studies, } 546 \text { patients) }\end{array}$ & $\begin{array}{l}4.2 \%(2.4-7.4,0) \\
\text { (14 studies, } 557 \text { patients) }\end{array}$ \\
\hline - PCGBD & $\begin{array}{l}98.7 \%(98.0-99.1,0) \\
\text { (33 studies, } 2203 \text { patients) }\end{array}$ & $\begin{array}{l}89.3 \%(86.6-91.5,84) \\
\text { ( } 38 \text { studies, } 11800 \text { pa- } \\
\text { tients) }\end{array}$ & $\begin{array}{l}15.1 \%(11.1-20.3,95) \\
\text { ( } 39 \text { studies, } 11997 \text { pa- } \\
\text { tients) }\end{array}$ & $\begin{array}{l}10.8 \%(8.3-13.9,76) \\
\text { (37 studies, } 3677 \text { patients) }\end{array}$ \\
\hline \multicolumn{5}{|c|}{$P$ value of statistical significance } \\
\hline - ETGBD vs. EUSGBD & 0.001 & 0.001 & 0.32 & 0.99 \\
\hline - ETGBD vs. PCGBD & 0.001 & 0.59 & 0.12 & 0.001 \\
\hline - EUSGBD vs. PCGBD & 0.001 & 0.001 & 0.56 & 0.001 \\
\hline
\end{tabular}

- Table 2 Pooled rate of adverse events subtypes.

\begin{tabular}{|c|c|c|c|}
\hline & ETGBD & EUSGBD & PCGBD \\
\hline \multicolumn{4}{|l|}{ Pooled rates, $95 \% \mathrm{Cl}, 1^{2} \%$} \\
\hline Bleeding & $\begin{array}{l}1.9 \%(1.1-3.1,0) \\
\text { (21 studies, } 1209 \text { patients) }\end{array}$ & $\begin{array}{l}4.3 \%(2.7-6.8,0) P=0.02 \\
(13 \text { studies, } 546 \text { patients) }\end{array}$ & $\begin{array}{l}2 \%(1.5-2.7,0) \\
\text { (37 studies, } 3597 \text { patients) }\end{array}$ \\
\hline Perforation & $\begin{array}{l}2 \%(1.2-3.2,0) \\
\text { ( } 21 \text { studies, } 1209 \text { patients) }\end{array}$ & $\begin{array}{l}3.7 \%(2.3-6,0) P=\mathbf{0 . 0 4} \\
(13 \text { studies, } 546 \text { patients })\end{array}$ & $\begin{array}{l}2 \%(1.4-2.9,0) \\
\text { (36 studies, } 3524 \text { patients) }\end{array}$ \\
\hline Bile leak/bile peritonitis & $\begin{array}{l}1.4 \%(0.8-2.5,0) \\
\text { (21 studies, } 1209 \text { patients) }\end{array}$ & $\begin{array}{l}2.9 \%(1.6-5.1,0) \\
\text { (13 studies, } 546 \text { patients) }\end{array}$ & $\begin{array}{l}2.7 \%(2.1-3.5,0) \\
\text { (37 studies, } 3597 \text { patients) }\end{array}$ \\
\hline Pancreatitis & $\begin{array}{l}5.1 \%(3.5-7.3,17) P=\mathbf{0 . 0 0 3} \\
(21 \text { studies, } 1209 \text { patients) }\end{array}$ & $\begin{array}{l}1.4 \%(0.7-3.1,0) \\
\text { (13 studies, } 546 \text { patients) }\end{array}$ & $\begin{array}{l}1.1 \%(0.7-1.7,0) \\
\text { (36 studies, } 3524 \text { patients) }\end{array}$ \\
\hline Stent occlusion & $\begin{array}{l}1.8 \%(0.9-3.6,0) \\
\text { (20 studies, } 1171 \text { patients) }\end{array}$ & $\begin{array}{l}2.6 \%(1.2-5.6,0) \\
(12 \text { studies, } 506 \text { patients) }\end{array}$ & $\begin{array}{l}1.8 \%(1.1-2.8,56) \\
\text { (36 studies, } 3524 \text { patients) }\end{array}$ \\
\hline Stent migration & $\begin{array}{l}2.2 \%(1.2-3.9,0) \\
\text { (20 studies, } 1171 \text { patients) }\end{array}$ & $\begin{array}{l}2.7 \%(1.3-5.4,0) \\
\text { (13 studies, } 546 \text { patients) }\end{array}$ & $\begin{array}{l}7.4 \%(5.5-10,79) P=\mathbf{0 . 0 1} \\
\text { (38 studies, } 3977 \text { patients) }\end{array}$ \\
\hline Mortality & $\begin{array}{l}16.6 \%(10.5-25.2,77) \\
\text { (13 studies, } 884 \text { patients) }\end{array}$ & $\begin{array}{l}26 \%(16.7-38.1,86) P=\mathbf{0 . 0 0 1} \\
(9 \text { studies, } 398 \text { patients })\end{array}$ & $\begin{array}{l}11.2 \%(8.7-14.1,83) \\
\text { (37 studies, } 3597 \text { patients) }\end{array}$ \\
\hline
\end{tabular}

\section{Technical success}

The calculated pooled rate of technical success was $83 \%(95 \%$ Cl 80.1-85.5, 95\%PI 72.3-90.2, $R^{2}=29$ ) with ETGBD, 95.3\% $\left(95 \% \mathrm{Cl} 92.8-96.9,95 \% \mathrm{PI} 92.6-97, R^{2}=0\right)$ with EUSGBD, and $98.7 \%\left(95 \% \mathrm{Cl} 98.0-99.1,95 \% \mathrm{PI} 98.1-99.1, R^{2}=0\right)$ with PCGBD. The technical success with EUSGBD was superior to that with $\operatorname{ETGBD}(P=0.001)$, whereas the PCGBD technical success was superior to both ETGBD and EUSGBD $(P=0.001)$ ( Fig. 1, $>$ Table 1 ).

\section{Clinical success}

The calculated pooled rate of clinical success was $88.1 \%(95 \% \mathrm{Cl}$ $83.6-91.4,95 \%$ PI $\left.70.3-95.9, I^{2}=50\right)$ with ETGBD, $96.7 \%(95 \%$ CI 94.0 - 98.2, $95 \% \mathrm{PI} 93.6-98.3, \mathrm{I}^{2}=0$ ) with EUSGBD, and $89.3 \%$ $\left(95 \% \mathrm{Cl} 86.6-91.5,95 \% \mathrm{PI} 68.8-96.9, R^{2}=84\right)$ with PCGBD. The clinical success with EUSGBD was superior to both ETGBD and PCGBD $(P=0.001)$, whereas the clinical success with ETGBD and PCGBD were comparable $(P=0.59)(\triangleright$ Fig. $2, \triangleright$ Table 1$)$. 


\begin{tabular}{|c|c|c|c|c|c|c|c|}
\hline \multirow{2}{*}{$\begin{array}{l}\text { Group by } \\
\text { drainage } \\
\text { route }\end{array}$} & \multirow[t]{2}{*}{ Study name } & \multicolumn{3}{|c|}{ Statistics for each study } & \multirow{2}{*}{\multicolumn{2}{|c|}{ Event rate and $95 \% \mathrm{Cl}$}} & \\
\hline & & Event rate & Lower limit & Upper limit & & & \\
\hline ETGBD & Chikara, 2017 ET & 0.939 & 0.788 & 0.985 & & & $\longrightarrow-$ \\
\hline ETGBD & Feretis, 1993 & 0.971 & 0.664 & 0.998 & & & \\
\hline ETGBD & Inoue, 2016 ET & 0.943 & 0.798 & 0.986 & & & - \\
\hline ETGBD & Itoi, 2008 & 0.972 & 0.827 & 0.996 & & & $\longrightarrow$ \\
\hline ETGBD & Itoi, 2017 ET & 0.892 & 0.845 & 0.926 & & & - \\
\hline ETGBD & Kjaer, 2007 & 0.875 & 0.676 & 0.959 & & & $=-$ \\
\hline ETGBD & Lee, 2011 & 0.870 & 0.665 & 0.957 & & & $-=$ \\
\hline ETGBD & Maekawa, 2013 & 0.861 & 0.707 & 0.941 & & & -- \\
\hline ETGBD & McCarthy, 2015 & 0.900 & 0.676 & 0.975 & & & \\
\hline ETGBD & Mutignani, 2009 & 0.828 & 0.647 & 0.926 & & & -- \\
\hline ETGBD & Nakatsu, 1997 & 0.972 & 0.678 & 0.998 & & & \\
\hline ETGBD & Oh, 2018 ET & 0.988 & 0.917 & 0.998 & & & -1 \\
\hline ETGBD & Tamada, 1991 & 0.643 & 0.376 & 0.843 & & & \\
\hline ETGBD & Higa, 2019 ET & 0.906 & 0.746 & 0.696 & & & $\longrightarrow-$ \\
\hline ETGBD & Schlenker, 2006 & 0.870 & 0.665 & 0.957 & & & -- \\
\hline ETGBD & Toyota, 2006 & 0.974 & 0.690 & 0.998 & & & \\
\hline ETGBD & Ogawa, 2008 & 0.636 & 0.339 & 0.857 & & & \\
\hline ETGBD & Pannala, 2008 & 0.980 & 0.874 & 0.997 & & & $\Rightarrow$ \\
\hline ETGBD & Yang, 2015 & 0.771 & 0.605 & 0.881 & & & - \\
\hline ETGBD & Widmer, 2015 ET & 0.914 & 0.851 & 0.952 & & & $\Rightarrow$ \\
\hline ETGBD & Yane, 2015 & 0.741 & 0.547 & 0.871 & & & \\
\hline ETGBD & Itoi, 2015 & 0.822 & 0.717 & 0.894 & & & $\rightarrow$ \\
\hline ETGBD & & 0.881 & 0.836 & 0.914 & & & $\bullet$ \\
\hline EUSGBD & Choi, 2014 & 0.992 & 0.885 & 1.000 & & & -1 \\
\hline EUSGBD & de la Serna-Higuera, 2013 & 0.958 & 0.575 & 0.997 & & & $=-1$ \\
\hline EUSGBD & Dollhopf, 2017 & 0.959 & 0.882 & 0.987 & & & - \\
\hline EUSGBD & Irani, 2015 & 0.969 & 0.650 & 0.998 & & & \\
\hline EUSGBD & Irani, 2017 EUS & 0.977 & 0.856 & 0.997 & & & $\longrightarrow$ \\
\hline EUSGBD & Jang, 2012 EUS & 0.983 & 0.783 & 0.999 & & & \\
\hline EUSGBD & Kahaleh, 2016 & 0.969 & 0.809 & 0.996 & & & $\longrightarrow$ \\
\hline EUSGBD & Oh, 2018 EUS & 0.994 & 0.911 & 1.000 & & & -1 \\
\hline EUSGBD & Takagi, 2016 & 0.971 & 0.664 & 0.998 & & & - \\
\hline EUSGBD & Teoh, 2016 EUS & 0.930 & 0.827 & 0.973 & & & $-?$ \\
\hline EUSGBD & Tyberg, 2016 EUS & 0.988 & 0.833 & 0.999 & & & \\
\hline EUSGBD & Walter, 2016 & 0.963 & 0.779 & 0.995 & & & $\longrightarrow$ \\
\hline EUSGBD & Higa, 2019 EUS & 0.950 & 0.821 & 0.987 & & & $\rightarrow$ \\
\hline EUSGBD & Widmer, 2015 EUS & 0.958 & 0.575 & 0.997 & & & $-=-$ \\
\hline EUSGBD & & 0.967 & 0.940 & 0.982 & & & $\bullet$ \\
\hline & & & & -1.00 & -0.50 & 0.50 & 1.0 \\
\hline
\end{tabular}

Fig. 2 Clinical success rates of gallbladder drainage methods. 
- Table 3 Pooled results from the analysis of prospective studies (total 7 studies, 331 patients).

\begin{tabular}{|c|c|c|c|c|}
\hline & Technical success & Clinical success & Adverse events & Recurrence \\
\hline \multicolumn{5}{|l|}{ Pooled rates, $95 \% \mathrm{Cl}, 12 \%$} \\
\hline $\begin{array}{l}\text { - ETGBD } \\
\text { (4 studies, } 87 \text { patients) }\end{array}$ & $84.3 \%(77.3-89.5,0)$ & $81.7 \%(74.1-87.5,12)$ & $12.6 \%(54.9-28.6,78)$ & $2.6 \%(0.8-7.8,0)$ \\
\hline $\begin{array}{l}\text { " EUSGBD } \\
\text { ( } 3 \text { studies, } 102 \text { patients) }\end{array}$ & $93.5 \%(86.3-97.1,0)$ & $97.7 \%(91.3-99.4,0)$ & $12.2 \%(4.4-29.7,0)$ & $6.1 \%(2.7-13.3,0)$ \\
\hline $\begin{array}{l}\text { - PCGBD } \\
\text { ( } 2 \text { studies, } 142 \text { patients) }\end{array}$ & $98.3 \%(93.3-99.6,0)$ & $87.7 \%(80.9-92.3,45)$ & $9.1 \%(2.4-28.8,45)$ & $7.3 \%(3.9-13.3,15)$ \\
\hline \multicolumn{5}{|c|}{$P$ value of statistical significance } \\
\hline - ETGBD vs. EUSGBD & 0.001 & 0.003 & 0.97 & 0.23 \\
\hline - ETGBD vs. PCGBD & 0.001 & 0.28 & 0.73 & 0.11 \\
\hline - EUSGBD vs. PCGBD & 0.001 & 0.02 & 0.86 & 0.72 \\
\hline
\end{tabular}

\section{Adverse events, disease recurrence, and mortality}

Data on adverse events were extracted and classified according to the ASGE lexicon definitions when possible. The majority of the studies, however, did not follow the ASGE lexicon definitions. Data were extracted as reported in the original studies. Details of the adverse event data extracted are provided in Table $3 \mathrm{~s}$.

The calculated pooled rates of all adverse events between ETGBD, EUSGBD, and PCGBD were comparable ( $\vee$ Table 1, Fig. $2 \mathbf{s})$. In the analysis of the adverse events subtypes, the $P$ value was statistically significant in the pooled rates of pancreatitis with $\operatorname{ETGBD}\left(5.1 \%, 95 \% \mathrm{Cl} 3.5-7.3, R^{2}=17, P=0.003\right)$, bleeding with EUSGBD $(4.3 \%, 95 \% \mathrm{Cl} 2.7-6.8, R=0, P=0.02)$, perforation with EUSGBD $\left(3.7 \%, 95 \% \mathrm{Cl} 2.3-6.0, R^{2}=0, P=0.04\right)$, and stent migration with PCGBD $\left(7.4 \%, 95 \% \mathrm{Cl} 5.5-10.0, I^{2}=79, P\right.$ $=0.01)$. The results for the pooled rates of adverse event subtypes with ETGBD, EUSGBD, and PCGBD are summarized in - Table 2 (see also Fig. 3 s, Fig.4s, Fig. 5 s, Fig. 6 s, Fig. 7 s, Fig. $8 \mathrm{~s}$ ).

The calculated pooled rate of disease recurrence was $4.6 \%$ $\left(95 \% \mathrm{Cl} 2.8-7.4, R^{2}=53\right)$ with ETGBD and $4.2 \%(95 \% \mathrm{Cl} 2.4-$ $\left.7.4, R^{2}=0\right)$ with EUSGBD. The rates were comparable between ETGBD and EUSGBD $(P=0.99)$, whereas the calculated pooled rate of disease recurrence with PCGBD was $10.8 \%(95 \% \mathrm{Cl} 8.3-$ $\left.13.9, I^{2}=76\right)$, which was significantly more $(P=0.001)$ than with ETGBD or EUSGBD ( $>$ Table 1, Fig.9s).

The pooled all-cause mortality rate was $16.6 \%$ (95\%Cl $10.5-$ $\left.25.2, R^{2}=77\right)$ with ETGBD, $26 \%\left(95 \% \mathrm{Cl} 16.7-38.1, R^{2}=86\right)$ with EUSGBD, and $11.2 \%\left(95 \% \mathrm{Cl} 8.7-14.1, I^{2}=83\right)$ with PCGBD. The pooled all-cause mortality rate with EUSGBD was significantly greater $(P=0.001)$ when compared with ETGBD or PCGBD ( Table 2, Fig.10s).

\section{Analysis of prospective studies}

No significant change was noted to the pooled rates except for the observed statistical significance of disease recurrence, which is now comparable between the groups. The observed heterogeneity was noted to decrease in the analysis of clinical success with ETGBD and PCGBD from prospectively designed studies. The results are summarized in $>$ Table 3 .

\section{Validation of meta-analysis results}

Sensitivity analysis

To assess whether any one study had a dominant effect on the meta-analysis, we excluded one study at a time and analyzed its effect on the main summary estimate. On this analysis, no single study significantly affected the outcome or the heterogeneity. Therefore, the inclusion or exclusion of either one of the studies by Irani et al. [5] and/or Dollhopf et al. [28] resulted in essentially the same pooled results.

\section{Heterogeneity}

We assessed dispersion of the calculated rates using the prediction interval $(\mathrm{PI})$ and $R^{2}$ percentage values. The $\mathrm{PI}$ gives an idea of the range of the dispersion and $R^{2}$ tell us what proportion of the dispersion is true vs. chance [19]. The pooled rates of technical and/or clinical success with ETGBD, EUSGBD, and PCGBD had narrow PIs with minimal to no heterogeneity. The pooled rates of adverse events and disease recurrence with PCGBD had considerable heterogeneity. The all-cause mortality data with all the modalities were also noted to have considerable heterogeneity.

\section{Publication bias}

Based on visual inspection of the funnel plot as well as quantitative measurement that used the Egger regression test, there was evidence of publication bias (Fig.11s, Egger's 2-tailed $P=$ 
0.001). Further statistics using the fail-Safe $\mathrm{N}$ test and Duval and Tweedie's "Trim and Fill" test revealed that the impact of the possible publication bias appeared to be minimal and would not change the calculated estimate or the conclusion of this meta-analysis.

\section{Discussion}

Our study demonstrates that EUSGBD has significantly better clinical success rates than ETGBD and/or PCGBD in the treatment of acute cholecystitis in high risk surgical patients. To the best of our knowledge, this study is the first meta-analysis comparing the outcomes of ETGBD, EUSGBD, and PCGBD.

Based on our analysis, EUSGBD demonstrated significantly superior technical success rate when compared with ETGBD (95.3\% vs. $83.0 \%, P=0.001)$. There are multiple explanations for this observation. The selective cannulation of the cystic duct can be technically difficult, especially in the presence of impacted stones and/or the tortuous nature of the cystic duct with its spiral valves of Heister. EUSGBD, on the other hand, is not affected by cystic duct anatomy. Nevertheless, EUSGBD has its own technical challenges including the need to identify an ideal site for transmural drainage and the technical demands of transmural stent placement. Accumulating experience with the procedure has shown promising results with regard to technical success [8]. Recent guidelines do recommend EUSGBD as a first-line modality in centers with high experience in the procedure [95].

Our analysis of clinical success revealed that EUSGBD demonstrated a significantly superior pooled rate when compared with ETGBD (96.7\% vs. $88.1 \%, P=0.001)$. This observation could be related to the recent widespread use of dedicated metal stents with flared ends in EUSGBD. By preventing migration, these stents provide sustained drainage of the gallbladder compared with double-pigtail plastic stents. Lumen-apposing metal stents generally have an overall wider diameter, aiding better drainage of gallbladder contents. The majority of the included studies were retrospective in nature and a selection bias on the use of ETGBD for common bile duct stones was unavoidable.

Our analysis of the adverse event subtypes revealed that EUSGBD had a significantly higher potential to cause bleeding (4.3\%, $P=0.02$ ) and perforation $(3.7 \%, P=0.04)$ compared with ETGBD, whereas ETGBD had a significantly higher rate of post-procedure pancreatitis compared with EUSGBD (5.1\%, $P$ $=0.003)$. It should be stated that the transmural nature of EUSGBD de facto creates an iatrogenic perforation of the stomach or the duodenum to the gallbladder, but that these perforations need to be made in a very controlled manner. PostETGBD pancreatitis is a well-established adverse event related to the fact that the procedure is performed as part of an ERCP. The pooled rates of all adverse events, and disease recurrence were comparable between ETGBD and EUSGBD.

Where does our analysis stand in relation to PCGBD? In this study, we have assessed our calculated outcomes with ETGBD and EUSGBD in relation to PCGBD, thereby contributing to the growing literature comparing endoscopic GBD with PCGBD.
Technical success with PCGBD (98.7\%) was significantly better than with ETGBD (83.0\%) or EUSGBD (95.3\%; $P=0.001)$. Clinical success with PCGBD (89.3\%) was comparable to ETGBD (88.1\%; $P=0.59)$, but significantly inferior to EUSGBD $(96.7 \%$; $P=0.001)$. Stent migration and/or dislodgement was a significantly frequent problem in PCGBD patients $(7.4 \% ; P=0.01)$ and the pooled rate of disease recurrence was significantly greater with PCGBD $(10.8 \% ; P=0.001)$ compared with ETGBD $(4.6 \%)$ or EUSGBD (4.2\%). In summary, although technically sound, PCGBD demonstrated significant stent dislodgement and disease recurrence, in addition to an inferior clinical success rate compared with endoscopic options, especially EUSGBD.

How does our study compare to other published works in literature? The only other published study that compared ETGBD, EUSGBD, and PCGBD is the three-way comparative study by Siddiqui et al. [92], which reported similar results to our study in terms of technical success; however, ETGBD seemed to have significantly lower clinical success compared with PCGBD and EUSGBD. Unlike any other study published to date, we report the pooled all-cause mortality rates. We noted that the allcause mortality in patients who underwent EUSGBD was $26 \%$, despite the very high clinical success rate (96.7\%), and was significantly more than ETGBD (16.6\%) or PCGBD (11.2\%; $P=$ $0.001)$. This result, however, needs to be interpreted with caution as it is limited by considerable heterogeneity and not all studies reported mortality data. Based on the study's clinical success definition, patients undergoing EUSGBD responded well with minimal disease recurrence. However, the probable explanation for the $26 \%$ all-cause mortality is that the majority of EUSGBD studies were conducted in patients in whom the overall survival was low to begin with and the studies adequately followed up their patients to report a mortality event, unlike the ETGBD and/or PCGBD studies.

The strengths of this review are as follows: systematic literature search with well-defined inclusion criteria, careful exclusion of redundant studies, inclusion of good quality studies with detailed extraction of data, rigorous evaluation of study quality, and statistics to establish and/or refute the validity of the results of our meta-analysis. Heterogeneity was minimal to zero in the overall primary outcome analysis and we were able to demonstrate the study design (prospective and retrospective) as the main reason behind the observed heterogeneity. There were limitations to this study, most of which are inherent to any meta-analysis. The included studies were not entirely representative of the general population and community practice, with most studies being performed in tertiary-care referral centers. Our analysis included studies that were retrospective in nature, which contributed to selection bias.

In conclusion, based on our meta-analysis of the various GBD modalities in the management of acute cholecystitis patients with high risk for surgery, EUSGBD demonstrated superior clinical success compared with ETGBD and/or PCGBD. Significant risk of perforation and bleeding can be expected with EUSGBD, whereas acute pancreatitis risk is significantly higher with ETGBD. PCGBD in this patient population was associated with a significantly higher chances of disease recurrence and stent dis- 
lodgement. The all-cause mortality seemed to be significantly more in the EUSGBD cohort; however, this was limited by considerable heterogeneity. We, therefore, recommend that EUSGBD be used as one of the first-line approaches when treating this patient population and is preferably performed in centers with high expertise owing to the chances of rare but serious adverse events.

\section{Competing interests}

Dr. Adler is a consultant for Boston Scientific.

\section{References}

[1] Csikesz NG, Tseng JF, Shah SA. Trends in surgical management for acute cholecystitis. Surgery 2008; 144: 283-289

[2] Winbladh A, Gullstrand P, Svanvik J et al. Systematic review of cholecystostomy as a treatment option in acute cholecystitis. HPB (Oxford) 2009; 11: 183-193

[3] Itoi T, Takada T, Hwang TL et al. Percutaneous and endoscopic gallbladder drainage for acute cholecystitis: international multicenter comparative study using propensity score-matched analysis. J Hepatobiliary Pancreat Sci 2017; 24: 362-368

[4] Chikara L, Shimoyama T, Igarashi T et al. Comparable efficacy of endoscopic transpapillary gallbladder drainage and percutaneous transhepatic gallbladder drainage in acute cholecystitis. Endosc Int Open 2018; 6: E594-E601

[5] Irani S, Ngamruengphong S, Teoh A et al. Similar efficacies of endoscopic ultrasound gallbladder drainage with a lumen-apposing metal stent versus percutaneous transhepatic gallbladder drainage for acute cholecystitis. Clin Gastroenterol Hepatol 2017; 15: 738-745

[6] Jang JW, Lee SS, Song TJ et al. Endoscopic ultrasound-guided transmural and percutaneous transhepatic gallbladder drainage are comparable for acute cholecystitis. Gastroenterology 2012; 142: 805-811

[7] Teoh AYB, Serna C, Penas I et al. Endoscopic ultrasound-guided gallbladder drainage reduces adverse events compared with percutaneous cholecystostomy in patients who are unfit for cholecystectomy. Endoscopy 2017; 49: 130-138

[8] Tyberg A, Saumoy M, Sequeiros EV et al. EUS-guided versus percutaneous gallbladder drainage: Isn't it time to convert? J Clin Gastroenterol 2018; 52: 79-84

[9] Moher D, Liberati A, Tetzlaff J et al. Preferred reporting items for systematic reviews and meta-analyses: the PRISMA statement. Ann Intern Med 2009; 151: 264-269

[10] Stroup DF, Berlin JA, Morton SC et al. Meta-analysis of observational studies in epidemiology: a proposal for reporting. Meta-analysis Of Observational Studies in Epidemiology (MOOSE) group. JAMA 2000; 283: 2008-2012

[11] Stang A. Critical evaluation of the Newcastle-Ottawa scale for the assessment of the quality of nonrandomized studies in meta-analyses. Eur J Epidemiol 2010; 25: 603-605

[12] Thompson SG, Pocock S]. Can meta-analyses be trusted? Lancet 1991; 338: 1127-1130

[13] Yokoe M, Hata J, Takada T et al. Tokyo Guidelines 2018: diagnostic criteria and severity grading of acute cholecystitis (with videos). J Hepatobiliary Pancreat Sci 2018; 25: 41-54

[14] Cotton PB, Eisen GM, Aabakken L et al. A lexicon for endoscopic adverse events: report of an ASGE workshop. Gastrointest Endosc 2010; 71: $446-454$
[15] DerSimonian R, Laird N. Meta-analysis in clinical trials. Control Clin Trials 1986; 7: 177-188

[16] Sutton AJ, Abrams KR, Jones DR et al. Methods for meta-analysis in medical research. New York: John Wiley \& Sons Ltd.; 2000: 205-228

[17] Higgins J, Thompson SG, Spiegelhalter DJ. A re-evaluation of randomeffects meta-analysis. J R Stat Soc Ser A Stat Soc 2009; 172: 137-159

[18] Riley RD, Higgins JP, Deeks JJ. Interpretation of random effects metaanalyses. BMJ 2011; 342: d549

[19] Mohan BP, Adler DG. Heterogeneity in systematic review and metaanalysis: how to read between the numbers. Gastrointest Endosc 2019; 89: 902-903

[20] Kanwal F, White D. Systematic reviews and meta-analyses in clinical gastroenterology and hepatology. Clin Gastroenterol Hepatol 2012; 10: $1184-1186$

[21] Higgins JP, Thompson SG, Deeks JJ et al. Measuring inconsistency in meta-analyses. BMJ 2003; 327: 557

[22] Guyatt GH, Oxman AD, Kunz R et al. GRADE guidelines: 7. Rating the quality of evidence - inconsistency. J Clin Epidemiol 2011; 64: 12941302

[23] Easterbrook P], Gopalan R, Berlin JA et al. Publication bias in clinical research. Lancet 1991; 337: 867-872

[24] Duval S, Tweedie R. Trim and fill: a simple funnel-plot-based method of testing and adjusting for publication bias in meta-analysis. Biometrics 2000; 56: 455-463

[25] Rothstein HR, Sutton AJ, Borenstein M. Publication bias in meta-analysis: prevention, assessment and adjustments. New York: John Wiley \& Sons; 2006

[26] Choi JH, Lee SS, Choi JH et al. Long-term outcomes after endoscopic ultrasonography-guided gallbladder drainage for acute cholecystitis. Endoscopy 2014; 46: 656-661

[27] de la Serna-Higuera C, Pérez-Miranda M, Gil-Simón P et al. EUS-guided transenteric gallbladder drainage with a new fistula-forming, lumenapposing metal stent. Gastrointest Endosc 2013; 77: 303-308

[28] Dollhopf M, Larghi A, Will U et al. EUS-guided gallbladder drainage in patients with acute cholecystitis and high surgical risk using an electrocautery-enhanced lumen-apposing metal stent device. Gastrointest Endosc 2017; 86: 636-643

[29] Feretis C, Apostolidis N, Mallas E et al. Endoscopic drainage of acute obstructive cholecystitis in patients with increased operative risk. Endoscopy 1993; 25: 392-395

[30] Inoue T, Okumura F, Kachi K et al. Long-term outcomes of endoscopic gallbladder stenting in high-risk surgical patients with calculous cholecystitis (with videos). Gastrointest Endosc 2016; 83: 905-913

[31] Irani S, Baron TH, Grimm IS et al. EUS-guided gallbladder drainage with a lumen-apposing metal stent (with video). Gastrointest Endosc 2015; 82: 1110-1115

[32] Itoi T, Sofuni A, Itokawa F et al. Endoscopic transpapillary gallbladder drainage in patients with acute cholecystitis in whom percutaneous transhepatic approach is contraindicated or anatomically impossible (with video). Gastrointest Endosc 2008; 68: 455-460

[33] Kahaleh M, Perez-Miranda M, Artifon EL et al. International collaborative study on EUS-guided gallbladder drainage: Are we ready for prime time? Dig Liver Dis 2016; 48: 1054-1057

[34] Kedia P, Sharaiha RZ, Kumta NA et al. Endoscopic gallbladder drainage compared with percutaneous drainage. Gastrointest Endosc 2015; 82: 1031-1036

[35] Kjaer DW, Kruse A, Funch-Jensen P. Endoscopic gallbladder drainage of patients with acute cholecystitis. Endoscopy 2007; 39: 304-308

[36] Lee TH, Park DH, Lee SS et al. Outcomes of endoscopic transpapillary gallbladder stenting for symptomatic gallbladder diseases: a multicenter prospective follow-up study. Endoscopy 2011; 43: 702-708 
[37] Maekawa S, Nomura R, Murase T et al. Endoscopic gallbladder stenting for acute cholecystitis: a retrospective study of 46 elderly patients aged 65 years or older. BMC Gastroenterol 2013; 13: 65

[38] McCarthy ST, Tujios S, Fontana RJ et al. Endoscopic transpapillary gallbladder stent placement is safe and effective in high-risk patients without cirrhosis. Dig Dis Sci 2015; 60: 2516-2522

[39] Mutignani M, lacopini F, Perri V et al. Endoscopic gallbladder drainage for acute cholecystitis: technical and clinical results. Endoscopy 2009; 41: 539-546

[40] Nakatsu T, Okada H, Saito K et al. Endoscopic transpapillary gallbladder drainage (ETGBD) for the treatment of acute cholecystitis. J Hepatobiliary Pancreat Surg 1997; 4: 31-35

[41] Oh D, Song TJ, Cho DH et al. EUS-guided cholecystostomy versus endoscopic transpapillary cholecystostomy for acute cholecystitis in high-risk surgical patients. Gastrointest Endosc 2019; 89: 289-298

[42] Takagi W, Ogura T, Sano T et al. EUS-guided cholecystoduodenostomy for acute cholecystitis with an anti-stent migration and anti-food impaction system; a pilot study. Therap Adv Gastroenterol 2016; 9: 19-25

[43] Tamada K, Seki H, Sato K et al. Efficacy of endoscopic retrograde cholecystoendoprosthesis (ERCCE) for cholecystitis. Endoscopy 1991; 23: $2-3$

[44] Walter D, Teoh AY, Itoi T et al. EUS-guided gall bladder drainage with a lumen-apposing metal stent: a prospective long-term evaluation. Gut 2016; 65: 6-8

[45] Abi-Haidar Y, Sanchez V, Williams SA et al. Revisiting percutaneous cholecystostomy for acute cholecystitis based on a 10-year experience. Arch Surg 2012; 147: 416-422

[46] Al-Jundi W, Cannon T, Antakia R et al. Percutaneous cholecystostomy as an alternative to cholecystectomy in high risk patients with biliary sepsis: a district general hospital experience. Ann R Coll Surg Engl 2012; 94: 99-101

[47] Anderson JE, Chang DC, Talamini MA. A nationwide examination of outcomes of percutaneous cholecystostomy compared with cholecystectomy for acute cholecystitis, 1998-2010. Surg Endosc 2013; 27: 3406-3411

[48] Atar E, Bachar GN, Berlin S et al. Percutaneous cholecystostomy in critically ill patients with acute cholecystitis: complications and late outcome. Clin Radiol 2014; 69: e247-e252

[49] Bakkaloglu H, Yanar H, Guloglu R et al. Ultrasound guided percutaneous cholecystostomy in high-risk patients for surgical intervention. World J Gastroenterol 2006; 12: 7179-7182

[50] Boules M, Haskins IN, Farias-Kovac M et al. What is the fate of the cholecystostomy tube following percutaneous cholecystostomy? Surg Endosc 2017; 31: 1707-1712

[51] Carrafiello G, D’Ambrosio A, Mangini M et al. Percutaneous cholecystostomy as the sole treatment in critically ill and elderly patients. Radiol Med 2012; 117: 772-779

[52] Cha BH, Song HH, Kim YN et al. Percutaneous cholecystostomy is appropriate as definitive treatment for acute cholecystitis in critically ill patients: a single center, cross-sectional study. Korean J Gastroenterol 2014; 63: 32-38

[53] Chang YR, Ahn Y], Jang JY et al. Percutaneous cholecystostomy for acute cholecystitis in patients with high comorbidity and re-evaluation of treatment efficacy. Surgery 2014; 155: 615-622

[54] Chok KSH, Chu FSK, Cheung TT et al. Results of percutaneous transhepatic cholecystostomy for high surgical risk patients with acute cholecystitis. ANZ J Surg 2010; 80: 280-283

[55] Chou CK, Lee KC, Chan CC et al. Early percutaneous cholecystostomy in severe acute cholecystitis reduces the complication rate and duration of hospital stay. Medicine (Baltimore) 2015; 94: e1096

[56] El-Gendi A, El-Shafei M, Emara D. Emergency versus delayed cholecystectomy after percutaneous transhepatic gallbladder drainage in
Grade II acute cholecystitis patients. J Gastrointest Surg 2017; 21: 284-293

[57] Flexer S, Peter M, Durham-Hall A et al. Patient outcomes after treatment with percutaneous cholecystostomy for biliary sepsis. Ann R Coll Surg Engl 2014; 96: 229-233

[58] Griniatsos ], Petrou A, Pappas P et al. Percutaneous cholecystostomy without interval cholecystectomy as definitive treatment of acute cholecystitis in elderly and critically ill patients. South Med J 2008; 101: 586-590

[59] Higa JT, Sahar N, Kozarek RA et al. EUS-guided gallbladder drainage with a lumen-apposing metal stent versus endoscopic transpapillary gallbladder drainage for the treatment of acute cholecystitis (with videos). Gastrointest Endosc 2019; 90: 483-492

[60] Horn T, Christensen SD, Kirkegard J et al. Percutaneous cholecystostomy is an effective treatment option for acute calculous cholecystitis: a 10-year experience. HPB (Oxford) 2015; 17: 326-331

[61] Hsieh YC, Chen CK, Su CW et al. Outcome after percutaneous cholecystostomy for acute cholecystitis: a single-center experience. J Gastrointest Surg 2012; 16: 1860-1868

[62] Hung Y-L, Chong S-W, Cheng C-T et al. Natural course of acute cholecystitis in patients treated with percutaneous transhepatic gallbladder drainage without elective cholecystectomy. J Gastrointest Surg 2019: doi:10.1007/s11605-019-04213-0

[63] Itoi T, Kawakami H, Katanuma A et al. Endoscopic nasogallbladder tube or stent placement in acute cholecystitis: a preliminary prospective randomized trial in Japan (with videos). Gastrointest Endosc 2015; 81: 111-118

[64] Jang WS, Lim JU, Joo KR et al. Outcome of conservative percutaneous cholecystostomy in high-risk patients with acute cholecystitis and risk factors leading to surgery. Surg Endosc 2015; 29: 2359-2364

[65] Li M, Li N, Ji W et al. Percutaneous cholecystostomy is a definitive treatment for acute cholecystitis in elderly high-risk patients. Am Surg 2013; 79: 524-527

[66] Lin WC, Chang CW, Chu CH. Percutaneous cholecystostomy for acute cholecystitis in high-risk elderly patients. Kaohsiung J Med Sci 2016; 32: 518-525

[67] Macri A, Scuderi G, Saladino E et al. Acute gallstone cholecystitis in the elderly: treatment with emergency ultrasonographic percutaneous cholecystostomy and interval laparoscopic cholecystectomy. Surg Endosc 2006; 20: 88-91

[68] McKay A, Abulfaraj M, Lipschitz J. Short- and long-term outcomes following percutaneous cholecystostomy for acute cholecystitis in high-risk patients. Surg Endosc 2012; 26: 1343-1351

[69] Melloul E, Denys A, Demartines N et al. Percutaneous drainage versus emergency cholecystectomy for the treatment of acute cholecystitis in critically ill patients: does it matter? World J Surg 2011; 35: 826833

[70] Morse BC, Smith JB, Lawdahl RB et al. Management of acute cholecystitis in critically ill patients: contemporary role for cholecystostomy and subsequent cholecystectomy. Am Surg 2010; 76: 708-712

[71] Nasim S, Khan S, Alvi R et al. Emerging indications for percutaneous cholecystostomy for the management of acute cholecystitis - a retrospective review. Int J Surg 2011; 9: 456-459

[72] Ni Q, Chen D, Xu R et al. The efficacy of percutaneous transhepatic gallbladder drainage on acute cholecystitis in high-risk elderly patients based on the Tokyo Guidelines: a retrospective case-control study. Medicine (Baltimore) 2015; 94: e1442

[73] Nikfarjam M, Shen L, Fink MA et al. Percutaneous cholecystostomy for treatment of acute cholecystitis in the era of early laparoscopic cholecystectomy. Surg Laparosc Endosc Percutan Tech 2013; 23: 474480

[74] Ogawa O, Yoshikumi H, Maruoka N et al. Predicting the success of endoscopic transpapillary gallbladder drainage for patients with 
acute cholecystitis during pretreatment evaluation. Can J Gastroenterol 2008; 22: 681-685

[75] Pang KW, Tan CH, Loh S et al. Outcomes of percutaneous cholecystostomy for acute cholecystitis. World J Surg 2016; 40: 2735-2744

[76] Pannala R, Petersen BT, Gostout C] et al. Endoscopic transpapillary gallbladder drainage: 10-year single center experience. Minerva Gastroenterol Dietol 2008; 54: 107-113

[77] Peters R, Kolderman S, Peters B et al. Percutaneous cholecystostomy: single centre experience in 111 patients with an acute cholecystitis. JBR-BTR 2014; 97: 197-201

[78] Rodriguez-Sanjuan JC, Arruabarrena A, Sanchez-Moreno L et al. Acute cholecystitis in high surgical risk patients: percutaneous cholecystostomy or emergency cholecystectomy? Am J Surg 2012; 204: 5459

[79] Sanjay P, Mittapalli D, Marioud A et al. Clinical outcomes of a percutaneous cholecystostomy for acute cholecystitis: a multicentre analysis. HPB (Oxford) 2013; 15: 511-516

[80] Schlenker C, Trotter JF, Shah RJ et al. Endoscopic gallbladder stent placement for treatment of symptomatic cholelithiasis in patients with end-stage liver disease. Am J Gastroenterol 2006; 101: 278-283

[81] Smith TJ, Manske JG, Mathiason MA et al. Changing trends and outcomes in the use of percutaneous cholecystostomy tubes for acute cholecystitis. Ann Surg 2013; 257: 1112-1115

[82] Toyota N, Takada T, Amano H et al. Endoscopic naso-gallbladder drainage in the treatment of acute cholecystitis: alleviates inflammation and fixes operator's aim during early laparoscopic cholecystectomy. J Hepatobiliary Pancreat Surg 2006; 13: 80-85

[83] Viste A, Jensen D, Angelsen JH et al. Percutaneous cholecystostomy in acute cholecystitis; a retrospective analysis of a large series of 104 patients. BMC Surg 2015; 15: 17

[84] Wang CH, Wu CY, Yang JC et al. Long-term outcomes of patients with acute cholecystitis after successful percutaneous cholecystostomy treatment and the risk factors for recurrence: a decade experience at a single center. PLoS One 2016; 11: e0148017

[85] Widmer J, Alvarez P, Sharaiha RZ et al. Endoscopic gallbladder drainage for acute cholecystitis. Clin Endosc 2015; 48: 411-420

[86] Yane K, Maguchi H, Katanuma A et al. Feasibility, efficacy, and predictive factors for the technical success of endoscopic nasogallbladder drainage: a prospective study. Gut Liver 2015; 9: 239-246
[87] Yang M], Yoo BM, Kim JH et al. Endoscopic naso-gallbladder drainage versus gallbladder stenting before cholecystectomy in patients with acute cholecystitis and a high suspicion of choledocholithiasis: a prospective randomised preliminary study. Scand J Gastroenterol 2016; 51: 472-478

[88] Yeo CS, Tay VW, Low JK et al. Outcomes of percutaneous cholecystostomy and predictors of eventual cholecystectomy. J Hepatobiliary Pancreat Sci 2016; 23: 65-73

[89] Zehetner J, Degnera E, Olasky J et al. Percutaneous cholecystostomy versus laparoscopic cholecystectomy in patients with acute cholecystitis and failed conservative management: a matched-pair analysis. Surg Laparosc Endosc Percutan Tech 2014; 24: 523-527

[90] Zerem E, Omerovic S. Can percutaneous cholecystostomy be a definitive management for acute cholecystitis in high-risk patients? Surg Laparosc Endosc Percutan Tech 2014; 24: 187-191

[91] Simorov A, Ranade A, Parcells J et al. Emergent cholecystostomy is superior to open cholecystectomy in extremely ill patients with acalculous cholecystitis: a large multicenter outcome study. Am J Surg 2013; 206: 935-940

[92] Siddiqui A, Kunda R, Tyberg A et al. Three-way comparative study of endoscopic ultrasound-guided transmural gallbladder drainage using lumen-apposing metal stents versus endoscopic transpapillary drainage versus percutaneous cholecystostomy for gallbladder drainage in high-risk surgical patients with acute cholecystitis: clinical outcomes and success in an international, multicenter study. Surg Endosc 2019; 33: $1260-1270$

[93] Jang JW, Lee SS, Park DH et al. Feasibility and safety of EUS-guided transgastric/transduodenal gallbladder drainage with single-step placement of a modified covered self-expandable metal stent in patients unsuitable for cholecystectomy. Gastrointest Endosc 2011; 74: 176-181

[94] Kirkegard J, Horn T, Christensen SD et al. Percutaneous cholecystostomy is an effective definitive treatment option for acute acalculous cholecystitis. Scand J Surg 2015; 104: 238-243

[95] Mori Y, Itoi T, Baron TH et al. Tokyo Guidelines 2018: management strategies for gallbladder drainage in patients with acute cholecystitis (with videos). J Hepatobiliary Pancreat Sci 2018; 25: 87-95 